\title{
International publications of authors from Bosnia and Herzegovina in Current Contents indexed publications in the first half of $2013^{\star}$
}

Alečković-Halilović M, Mešić E, Sinanović O, Zukić S, Mustedanagić J. Carnitine palmitoyl transferase deficiency--unrecognized cause of recurrent acute kidney injury. Ren Fail. 2013;35(5):732-4. doi: 10.3109/0886022X.2013.780979. Epub 2013 Apr 8.

Nephrology, Dialysis and Kidney Transplantation Department, University Clinical Centre Tuzla, Tuzla, Bosnia and Herzegovina.

Metabolic myopathies represent a small percentage of rhabdomyolysis causes that could lead to acute kidney injury (AKI). This could be prevented if this condition is suspected and timely treated. Carnitine palmityl transferase (CPT) deficiency is the most frequent metabolic myopathy and should be considered whenever recurrent myoglobinuria is suspected, and distinguished from the second frequent one, McArdle disease. We present a case of a patient with two medically misinterpreted episodes of AKI in whom the subsequent diagnosis of CPT deficiency was established based on high index of clinical suspicion and correlation of clinical manifestations to specific metabolic defects. Application of simple measures and lifestyle changes improved our patient's life quality and prevented potential new life-threatening complications.

Alić A, Prašović S, Hodžić A, Beširović H, Rešidbegović E, Omeragić J. Fatal verminous pharyngitis and esophagitis caused by Streptocara incognita in mute swans (Cygnus olor). Avian Dis. 2013 Mar;57(1):147-51.
Department of Pathology, Faculty of Veterinary Medicine, University of Sarajevo, Zmaja od Bosne 90, 71000 Sarajevo, Bosnia and Herzegovina.

Streptocara spp. infections are reported to cause gastritis, proventriculitis, esophagitis, and pharyngitis in various waterfowls, especially diving ducks. In the present paper, we describe severe fatal diphtheritic pharyngitis and esophagitis caused by Streptocara incognita in three female mute swans (Cygnus olor) in Bosnia and Herzegovina. Prior to death, the swans were showing signs of lethargy, anorexia, and reluctance to move. At necropsy, in all swans severe diphtheritic pharyngitis and esophagitis with deep, dark red hemorrhagic ulcerations were observed. Numerous thin, white, up to $1-\mathrm{cm}$-long nematodes, identified as $\mathrm{S}$. incognita, were observed embedded in the pharyngeal and esophageal mucosa under the diphtheritic membranes. Histopathology revealed severe fibrinonecrotic inflammation with numerous crosssections of the parasites. To the authors' knowledge, this is the first report of severe, fatal streptocariasis in mute swans.

Begić $\mathrm{H}$, Tahirović $\mathrm{H}$. The impact of delayed cardiac surgery on the postnatal growth of children with congenital heart disease in Bosnia and Herzegovina. Coll Antropol. 2013 Jun;37(2):50713.

University of Tuzla, University Clinical Centre, Department of Paediatrics, Tuzla, Bosnia and Herzegovina.

${ }^{\star}$ Data for this survey were collected from PubMed database using the keywords Bosnia and Herzegovina and 2013. 
The aim of this study was to evaluate preoperative and postoperative growth in children with congenital heart disease (CHD) when cardio-surgical treatment is delayed. Growth data were analysed on 116 children with various types of CHD (cyanotic lesions (Group 1), left to right shunt (Group 2) and obstructive lesions (Group 3)), who underwent cardiac surgery after a certain period of waiting. Preoperatively, during the time (median $1.13(0.55-2.39)$ ) years of waiting for surgery, their mean weight $\mathrm{z}$-score decreased from $-1.38(+/-1.19)$ to $-1.41(+/-1.28)$, and their mean height $\mathrm{z}$-score from $-0.65(+/-1.41)$ to $-0.81(+/-1.36)$. Children in Group 1 developed a significant linear growth deficit, in Group 2 weight was more affected than height, while in Group 3 both growth parameters were gradually slowly, but not significantly reduced. Postoperatively weight and height $\mathrm{z}$ scores, although they showed a linear trend of improvement for all three groups, remained significantly reduced for two years after surgery. At the time of the last examination at the age $9.11(5.66-13.10)$ years, the mean height $\mathrm{z}$ score $-0.16(+/-1.28)$, was significantly reduced $\mathrm{p}<$ 0.0001 , than predicted height $0.23(+/-0.82)$. Growth catch-up was related to age at surgery and preoperative growth deficit. Delayed cardiac surgery in children with CHD aggravated growth deficit and caused slow and incomplete postoperative growth catch-up.

Ćosić A, Ferhatović L, Banožić A, Kraljević S, Marić A, Sapunar D, Puljak L. Pain catastrophizing changes during the menstrual cycle. Psychol Health Med. 2013 Feb 26. [Epub ahead of print]

School of Health Sciences, University of Mostar, Bijeli brijeg b.b. , Mostar , 88000, Bosnia and Herzegovina.

Pain catastrophizing is an important predictor of pain intensity and pain-related outcomes. Many studies have shown that the level of this phenomenon is higher in women compared to men. The aim of this study was to investigate whether there is a difference in pain catastrophizing in women during the different phases of their menstrual cycle and whether there is a difference in pain catastrophizing depending on the history of childbirth and dysmenorrhea. A prospective study was conducted among 149 healthy women aged 18-35, with a regular menstrual cycle, 80 of which were nulliparous. The participants filled a sociodemographic questionnaire at the enrollment and the Pain Catastrophizing Scale on the 1st, 12th, and 20th day of the menstrual cycle. Pain catastrophizing scores, including all the subscales, significantly varied throughout the menstrual cycle, being highest on the first day of menstrual cycle and declining subsequently. Pain catastrophizing scores were higher in nulliparous than in parous women. Higher pain catastrophizing scores on the first day of the menstrual cycle were found in dysmehorrhoic women and women who regularly use analgesics for dysmenorrhea. Knowing that pain catastrophizing varies throughout the menstrual cycle may help in creating interventions for pain prevention and treatment in cycling women.

\section{Duranović M, Šehić S. The speed of articulatory movements involved in speech production in children with dyslexia. J Learn Disabil. 2013 May- Jun;46(3):278-86. doi: 10.1177/0022219411419014. Epub 2011 Nov 4.}

Faculty of Education and Rehabilitation, Tuzla University, Tuzla, Bosnia and Herzegovina.

A group of children with dyslexia (mean ages 9 and 14 years) was studied, together with group of children without dyslexia matched for age. Participants were monolingual native speakers of the Bosnian language with transparent orthography. In total, the diagnostic tests were performed with 41 children with dyslexia and 41 nondyslexic children. The participants were asked to produce monosyllables, $/ \mathrm{pa} /$, $/ \mathrm{ta} /$, and $/ \mathrm{ka} /$, and the trisyllable /pataka/, as fast as possible. Analysis was undertaken in four ways: (1) time of occlusion duration for plosives (duration of stop), (2) voice onset time for plosives, (3) diadochokinetic rate--articulators rate measured by pronunciation of monosyllables and the trisyllable, and (4) time of moving articulators from one gesture to another-time of interval length (from the explosion of one plosive to the start of the explosion of another plosive). The results suggest that children with dyslexia have significant problems with the speed of articulatory movements involved in speech production.

\section{Gegić M, Numanović F, Delibegović Z, Tihić N, Nurkić M, Hukić M. The importance of serological tests implementation in disseminated candidiasis diagnose. Coll Antropol. 2013 Mar;37(1):157-63.}

Tuzla University Clinic Centre, Clinic for Laboratory Diagnosis, Department of Microbiology, Tuzla, Bosnia and Herzegovina.

Candidiasis is defined as an infection or disease caused by a fungus of the genus Candida. Rate of disseminated candidiasis increases with the growth of the number of immunocompromised patients. In the the last few decades the incidence of disseminated candidiasis is in growth as well as the mortality rate. The aim of this survey is to show the importance of serological tests implementation in disseminated candidiasis diagnose. This is a prospective study involving 60 patients with malign diseases with and without clinical signs of disseminated candidiasis and 30 healthy people who represent the control group. Apart from 
hemoculture, detection of circulating mannan antigen and adequate antibodies of Candida species applying comercial ELISA test was determined in each patient. This survey deals with relevant factors causing disseminated candidiasis. This survey showed that the group of patients with clinical signs of disseminated candidiasis had more patients with positive hemoculture to Candida species, then the group of patients without clinical signs of disseminated candidiasis. The number of patients being examined and positive to antigens and antibodies was higher $(\mathrm{p}<0.01)$ in the group of patients with clinical signs of disseminated candidiasis $(7 / 30 ; 23.3 \%)$, then in the group of patients without clinical signs of disseminated candidiasis $(0 / 30 ; 0 \%)$ : Average value of titra antigen was statistically higher $(\mathrm{p}<0.001)$ in patients with Candida spp. positive hemocultures rather then in patients with Candida spp. negative hemocultures. In the group of patients with clinical signs of disseminated candidiasis 6/30 (20\%) of patients had Candida spp.positive hemocultures while in the group of patients without clinical signs of disseminated candidiasis $1 / 30(3.3 \%)$ of patients had Candida spp. positive hemocultures, which was considerably higher $(\mathrm{p}<0.05)$. Correlation of results of hemoculture and mannan antigens and antibodies in patients with disseminated candidiasis were statistically significant, while correlation of results of hemoculture and antibodies was insignificant. Because of low sensitivity of hemoculture and time needed for isolation of Candida spp., introducing serological tests in regular procedures would speed disseminated candidiasis diagnose.

Jegdić V, Rončević Ž, Škrabić V. Physical fitness in children with type 1 diabetes measured with six-minute walk test. Int J Endocrinol. 2013;2013:190454. doi: 10.1155/2013/190454. Epub 2013 Jun 27.

Department of Pediatrics, University Hospital, 88000 Mostar, Bosnia and Herzegovina.

Aim/Hypothesis. To examine whether children with DMT1 are less physically fit than healthy children and to assess whether an elevated level of HbA1c was associated with decreased physical fitness among children with diabetes. Methods. The study was conducted using case-control methodology. The cases were 100 children with T1DM, 7-17,9 years. Study subjects underwent a 6MWT, where distance measured, heart rate, and oxygen saturation was recorded. Results. Results of the 6MWT for children with T1DM and controls were $601.3 \pm 86.1$ meters versus $672.1 \pm 60.6$ meters, respectively $(\mathrm{P}<0.001)$. The cases were divided into two subgroups, one with $\mathrm{HbA}$ lc levels $>8 \%$ and one with $\mathrm{HbAlc}<8 \%$. Results for both groups were inferior to the controls $(\mathrm{P}<0.001)$. The posttest pulse rate in all subjects was higher than the pretest pulse rate $(\mathrm{P}<0.001)$. Pulse oxygen levels were lower than controls at the pretest measurement $(\mathrm{P}<0.001)$, and for both cases and controls, pulse oxygen levels decreased after test $(P=0.004)$. However, the change in oxygen saturation did not differ between the groups $(\mathrm{P}=0.332)$. Conclusions. Children with T1D are less fit than matched controls. The level of HbAlc did not affect the physical fitness of children with T1D.

\section{Kovačević L, Fatur-Cerić V, Hadžić N, Čakar J, Primorac D, Marjanović D. Haplotype data for 23 Y-chromosome markers in a reference sample from Bosnia and Herzegovina. Croat Med J. 2013 Jun;54(3):286-90.}

University in Sarajevo, Zmaja od Bosne 8, 71000 Sarajevo, Bosnia and Herzegovina.

AIM: To detect polymorphisms of 23 Y-chromosomal short tandem repeat (STR) loci, including 6 new loci, in a reference database of male population of Bosnia and Herzegovina, as well as to assess the importance of increasing the number of Y-STR loci utilized in forensic DNA analysis. METHODS: The reference sample consisted of 100 healthy, unrelated men originating from Bosnia and Herzegovina. Sample collection using buccal swabs was performed in all geographical regions of Bosnia and Herzegovina in the period from 2010 to 2011. DNA samples were typed for 23 Y STR loci, including 6 new loci: DYS576, DYS481, DYS549, DYS533, DYS570, and DYS643, which are included in the new PowerPlex ${ }^{\oplus}$ Y 23 amplification kit. RESULTS: The absolute frequency of generated haplotypes was calculated and results showed that 98 samples had unique Y 23 haplotypes, and that only two samples shared the same haplotype. The most polymorphic locus was DYS418, with 14 detected alleles and the least polymorphic loci were DYS389I, DYS391, DYS437, and DYS393. CONCLUSION: This study showed that by increasing the number of highly polymorphic Y STR markers, to include those tested in our analysis, leads to a reduction of repeating haplotypes, which is very important in the application of forensic DNA analysis.

\section{Kravić N, Pajević I, Hasanović M. Surviving genocide in Srebrenica during the early childhood and adolescent personality. Croat Med J. 2013 Feb;54(1):55-64. \\ Department of Psychiatry, Tuzla University Clinical Center, Trnovac bb, 75000 Tuzla, Bosnia and Herzegovina.}

AIM: To examine how the experience of genocide in Srebrenica in the early childhood (ages 1-5) influences the psychological health in adolescence. METHODS: 
This study included 100 school-attending adolescents, age 15-16 (born in 1990-91) who were divided in two groups according to the place of residence from 19921995: the Srebrenica group - adolescents who lived in Srebrenica during the siege and the non-Srebrenica group who lived in the "free territory," were not wounded, and experienced no losses. We used the socio-demographic questionnaire created for the purposes of our study and the War Trauma Questionnaire, Posttraumatic Stress Reactions Questionnaire, Self-report Depressive Scale (Zung), Freiburg Personality Inventory, and the Lifestyle Questionnaire. RESULTS: Srebrenica adolescents experienced significantly more traumatic experiences $(14.26 \pm 3.11$ vs $4.86 \pm 3.16, \mathrm{P}<0.001)$. Although there was no signifcant difference in the total score of posttraumatic stress reactions and intensity of depression between the two groups, significantly higher scores of posttraumatic stress reaction were noticed for several specific questions. The most prominent defense mechanisms in both groups were projection, intellectualization, and reactive formation. Srebrenica adolescents had higher sociability levels $(34.7 \%$ vs $16.0 \%, \chi(2)=7.231$, $\mathrm{P}=0.020)$. CONCLUSION: Srebrenica adolescents reported significantly more severe PTSD symptoms and significantly greater sociability. Our findings could be used for planning treatment and improving communication and overcoming traumas in war-affected areas.

Markota D, Markota I, Starčević B, Tomić M, Prskalo Z, Brizić I. Prevention of contrast-induced nephropathy with $\mathrm{Na} / \mathrm{K}$ citrate. Eur Heart J. 2013 Aug;34(30):2362-7. doi: 10.1093/eurheartj/eht009. Epub 2013 Jan 24.

Department of Cardiology, University Clinical Hospital Mostar, Mostar, Bosnia and Herzegovina.

AIMS: Contrast-induced nephropathy (CIN) is a frequent complication of many radiological procedures involving the application of contrast media. It represents a significant health problem that causes the increase in mortality, morbidity, and medical costs. For the prevention of CIN, a number of methods have been proposed to be effective. Among them, alkalinization of urine takes an important place. Although the $\mathrm{Na} / \mathrm{K}$ citrate is a well-known agent for urine alkalinization, it has not been studied in the prevention of CIN. METHODS AND RESULTS: Two hundred and two patients who underwent coronary angiography were included in the study. They were randomized into groups receiving the drug $\mathrm{Na} / \mathrm{K}$ citrate per os and to the control group. Serum creatinine and glomerular filtration rate were determined in all patients immediately before coronary angiography, and $48 \mathrm{~h}$ after the procedure. CIN criteria were a creatinine increase of $>25 \%$, reduction in the glomerular filtration rate by $>25 \%$, or an increase in serum creatinine of $>44$ $\mu \mathrm{mol} / \mathrm{L}$. The incidence of $\mathrm{CIN}$ in the group receiving $\mathrm{Na} / \mathrm{K}$ citrate was significantly lower when compared with the control group (4\% compared with $20 \%$, P = 0.0001). Patients who had a urine $\mathrm{pH}<6$ had a more than ten-fold higher incidence of contrast nephropathy compared with patients whose urine $\mathrm{pH}$ was $>6$. CONCLUSION: Alkalinization of urine using the $\mathrm{Na} / \mathrm{K}$ citrate may reduce the incidence of CIN.

\section{Markotić F, Černi Obrdalj E, Zalihić A, Pehar R, Hadžiosmanović Z, Pivić G, Durasović S, Grgić V, Banožić A, Sapunar D, Puljak L. Adherence to pharmacological treatment of chronic nonmalignant pain in individuals aged 65 and older. Pain Med. 2013 Feb;14(2):247-56. doi: 10.1111/pme.12035. Epub 2013 Jan 31.}

Office for monitoring and quality improvement, Clinical Hospital Mostar, Mostar, Bosnia and Herzegovina.

BACKGROUND: Medication nonadherence is a frequent problem in the treatment of chronic conditions. OBJECTIVE: To study the adherence to pharmacological treatment of chronic nonmalignant pain, as well as factors and patient attitudes related to nonadherence in patients aged $\geq 65$ years. METHODS: The cross-sectional study was conducted with a self-administered questionnaire among 100 patients aged $\geq 65$ years by five family physicians at the Health Care Centre Mostar, Bosnia and Herzegovina. RESULTS: According to their own statements, $57 \%$ of the patients were nonadherent, while $84 \%$ exhibited some form of nonadherence on the Morisky scale. The patients reported a mean pain intensity of $6.6 \pm 2.2$ on a visual analog scale. The most common deviation from the prescribed therapy was self-adjustment of the dose and medical regimen based on the severity of pain. Polymedication correlated positively with nonadherence. Nonsteroidal anti-inflammatory drugs were the most frequently prescribed medications. The majority of the participants (59\%) believed that higher pain intensity indicates progression of the disease, and half of the participants believed that one can easily become addicted to pain medications. Nonadherence was associated with patient attitudes about addiction to analgesics and ability of analgesics to control pain. CONCLUSION.: High pain intensity and nonadherence found in this study suggest that physicians should monitor older patients with chronic nonmalignant pain more closely and pay more attention to patients' beliefs regarding analgesics to ensure better adherence to pharmacological therapy.

Martinović-Bevanda A, Radić N.

Spectrophotometric sequential injection determination of D-penicillamine based on a 
complexation reaction with nickel ion. Anal Sci. 2013;29(6):669-71.

Department of Chemistry, Faculty of Science and Education, University of Mostar, Bosnia and Herzegovina.

A simple and sensitive spectrophotometric method, based on reaction between $\mathrm{Ni}$ (II) ion and $\mathrm{D}$-penicillamine (PEN), was developed. The proposed SIA system enhanced the analytical applicability of the reaction of complexation, and allowed the determination of PEN in the concentration range of $3.0 \times 10(-6)-2.0 \times 10$ (4) $\mathrm{mol} \mathrm{L}(-1)$ with a sampling rate of $200 \mathrm{~h}(-1)$. With the proposed SIA system, PEN could be accurately determinated up to $0.9 \mathrm{nmol}$ quantity. The method was successfully applied to the determination of PEN in laboratory samples and pharmaceuticals.

Mirjanić-Azarić B, Rizzo M, Šormaz Lj, Stojanović D, Uletilović S, Sodin-Semrl S, Lakota K, Artenjak A, Marc J, Černe D. Atorvastatin in stable angina patients lowers CCL2 and ICAM1 expression: Pleiotropic evidence from plasma mRNA analyses. Clin Biochem. 2013 Jun 20. pii: S0009-9120(13)00283-X. doi: 10.1016/j. clinbiochem.2013.06.006. [Epub ahead of print]

Clinical Centre Banja Luka, Department of laboratory diagnostics Banja Luka, Republic of Srpska, Bosnia and Herzegovina.

OBJECTIVE: Statin pleiotropy is still an evolving concept, and the lack of clarity on this subject is due at least in part to the lack of a definitive biomarker for statin pleiotropy. Using plasma mRNA analysis as a novel research tool for the non-invasive in vivo assessment of gene expression in vascular beds, we hypothesised that atorvastatin lowers the plasma mRNA level from statin pleiotropy-target genes, and the reduction is independent of the reduction of low-density lipoprotein cholesterol (LDL-C). DESIGN AND METHODS: Forty-four patients with stable angina received atorvastatin therapy $(20 \mathrm{mg} /$ day, 10weeks). Plasma chemokine (C-C motif) ligand 2 (CCL2) and intercellular adhesion molecule-1 (ICAM1) mRNA levels and their protein concentrations (MCP-1, sICAM-1) were analysed before and after the treatment. Plasma vascular adhesion molecule-1 (sVCAM-1) concentrations were also analysed. RESULTS: Atorvastatin lowered plasma mRNA levels (CCL2: $-31.76 \%, \mathrm{p}=0.037$; ICAM1: $-34.09 \%, \mathrm{p}<0.001)$ and MCP-1 protein concentration $(-18.88 \%, \mathrm{p}=0.008)$ but did not lower sICAM-1 and sVCAM-1 protein concentrations, and the decreases appeared to be independent from the lowering of LDL-C. The plasma mRNA levels correlated with their protein concentrations following statin treatment only. CONCLUSION: Our results signifi- cantly strengthen the clinical evidence in support of statin pleiotropy. Furthermore, this unique simultaneous measurement of plasma mRNAs and their protein concentrations offers an advanced non-invasive in vivo assessment of the circulation pathology.

Nefić $H$, Handžic I. The effect of age, sex, and lifestyle factors on micronucleus frequency in peripheral blood lymphocytes of the Bosnian population. Mutat Res. 2013 Apr 30;753(1):1-11. doi: 10.1016/j.mrgentox.2013.03.001. Epub 2013 Mar 7.

Department of Biology, Faculty of Science, University of Sarajevo, Zmaja od Bosne 33-35, Sarajevo 71000, Bosnia and Herzegovina.

This study confirmed that the frequency of human lymphocyte biomarkers measured with the cytokinesis-block micronucleus cytome (CBMNcyt) assay, is associated with age, sex, and lifestyle factors. Cytogenetic analysis was carried out on samples from 100 healthy individuals living in Bosnia and Herzegovina. Cells were cytologically scored for viability status, defined by the proportion of necrotic and apoptotic cells; mitotic status, corresponding to the proportion and ratios of mono-, bi- and multinucleated cells; the nuclear division index and chromosomal damage, determined by the presence of micronuclei, nucleoplasmic bridges or nuclear buds of bi-nucleated cells. Ageing is positively associated with the frequency of cytogenetic biomarkers. The micronucleus frequency in females was significantly higher than the micronucleus frequency in males. The micronucleus frequency is positively associated with family history of cancer. Furthermore, it is positively correlated with smoking: the frequency is higher in male subjects with a smoking habit than in female smokers. However, alcohol is observed to decrease the frequency of apoptotic cells in human lymphocytes. The frequency of micronuclei was positively correlated with exposure to medication. Lastly, the frequency of nuclear buds and apoptotic and necrotic cells negatively correlated with exposure to radiation.

Obrdalj EČ, Sesar K, Šantić Ž, Klarić M, Sesar I, Rumboldt M. Trauma symptoms in pupils involved in school bullying--a cross sectional study conducted in Mostar, Bosnia and Herzegovina. Coll Antropol. 2013 Mar;37(1):11-6.

University of Mostar, School of Medicine, Department of Family Medicine, Mostar, Bosnia and Herzegovina.

To determine the association between involvement in school bullying and trauma symptoms and to find whether children with presence of trauma symptoms 
participate in school bullying more as victims, as bullies or as bully/victims. The study included 1055, 6th to 8th grade (12-14 years of age) elementary school pupils from the western part of Mostar, The pupils were self-interviewed using a Questionnaire on School Violence developed in 2003 and validated in Croatia, and Trauma Symptoms Check List for Children (TSCC). The pupils involved in the school violence, either as victims, bullies, bully/victims had significantly more trauma symptoms than the not involved. Involvement in school bullying as a bully/ victim was a strong indicator of trauma symptoms, particularly anxiety, anger, posttraumatic stress, dissociation, obvious dissociation, and dissociation fantasy symptoms, while the victims of school violence had the highest odds ratio for the development of depressive symptoms. There is strong association between bullying and trauma symptoms in young adolescents. From our results, emphasis should be placed at the regularly screening on bullying in praxis of family physicians and regularly conduction of preventive measures and early intervention in every primary school.

Pašić F, Salkić NN. Predictive score for anastomotic leakage after elective colorectal cancer surgery: a decision making tool for choice of protective measures. Surg Endosc. 2013 May 25. [Epub ahead of print]

Department of Surgery, University Clinical Center Tuzla, Tuzla, Bosnia and Herzegovina.

BACKGROUND: Anastomotic leakage is the most severe complication after colorectal surgery and a major cause of postoperative morbidity and mortality. We aimed to identify a predictive score for postoperative leakage after colorectal cancer surgery and to evaluate its usefulness in assessing various protective measures. METHODS: A total of 159 patients were divided into test (79 patients) and validation (40 patients) groups in order to identify the risk factors and construct the predictive score. The remaining 40 patients (intervention group) were prospectively evaluated with the application of protective measures guided by risk stratification according to the predictive score. RESULTS: A total of 23 of 159 (14.5\%) patients had anastomotic leakage, with 7 of 23 (30.4\%) of them needing reoperation. 11 of 159 (6.9\%) patients died, with 10 (6.3\%) deaths directly associated with anastomotic leakage. The rate of leakage in the test and validation groups (nonintervention group) was 22 of 119 (18.5\%), while the rate of leakage in the intervention group was 3 of $40(7.5 \%)$. The odds ratio for anastomotic leakage in the intervention group was 0.23 compared to the nonintervention group, with a relative risk reduction of $73 \%$ for unfavorable event. The number needed to treat was 8 patients. There were also 10 of $119(8.4 \%)$ deaths in the nonintervention group compared to 1 of $40(2.5 \%)$ in the intervention group (Fisher's test; $\mathrm{p}=0.18$ ). CONCLUSIONS: Our simple predictive score may be a valuable decision making tool that can help surgeons reliably identify patients at high risk for postoperative anastomotic leakage and apply guided intraoperative protective measures.

Pojskić N, Silajdžić E, Kalamujić B, Kapur-Pojskić L, Lasić L, Tulić U, Hadžiselimović R. Polymorphic Alu insertions in human populations of Bosnia and Herzegovina. Ann Hum Biol. 2013 Mar;40(2):1815. doi: 10.3109/03014460.2012.756063. Epub 2013 Jan 30 .

Institute for Genetic Engineering and Biotechnology, Zmaja od Bosne 8 Kampus, 71000 Sarajevo, Bosnia and Herzegovina.

BACKGROUND: From a demographic and genetic perspective, Bosnia and Herzegovina is interwoven with a number of differentially isolated local populations of indigenous people with different population and religious backgrounds. AIM: In order to estimate their genetic structure, this study investigated the frequencies of 10 Alu polymorphic loci in 10 regional populations distributed across Bosnia and Herzegovina. Genetic differentiation among the three major population groups in Bosnia and Herzegovina was estimated. SUBJECTS AND METHODS: DNA from 506 unrelated individuals was extracted from buccal swabs using the salting-out extraction method. Each DNA sample was PCR-amplified using locus-specific primers. RESULTS: Gene diversity values showed similarity in all analysed populations and ranged from $0.305-0.328$. FST values for all loci showed that most variability is found within populations. Overall FST for all loci and AMOVA indicated that most variability was detected within populations. CONCLUSION: Results of this study are in agreement with the previous studies, indicating that the three populations inBosnia and Herzegovina have the same genetic background. There is no significant differentiation among regional populations, pointing to absence of geographic influence. The Bosnian population is clearly located within the European gene pool.

Salkić NN, Alibegović E, Jovanović P. Endoscopic appearance of duodenal mucosa in Whipple's disease. Gastrointest Endosc. 2013 May;77(5):8223; discussion 823. doi: 10.1016/j.gie.2013.01.016. Epub 2013 Mar 8.

Department of Gastroenterology and Hepatology, University Clinical Centre Tuzla, Tuzla, Bosnia and Herzegovina.

No abstract available. 
Skenderi F, Krakonja F, Vranić S. Infarcted fibroadenoma of the breast: report of two new cases with review of the literature. Diagn Pathol. 2013 Feb 27;8:38. doi: 10.1186/1746-1596-8-38.

\section{Department of Pathology, Clinical Center of the University of Sarajevo, Bolnička 25, Sarajevo, Bosnia and Herzegovina.}

INTRODUCTION: Fibroadenomas are the most common benign breast tumors in young women. Infarction is rarely observed in fibroadenomas and when present, it is usually associated with pregnancy or lactation. Infarction can exceptionally occur as a complication of previous fine-needle aspiration biopsy or during lactation and pregnancy. MATERIALS AND METHODS: Retrospective review of 650 cases of fibroadenomas diagnosed at our institution during the 8 -years period identified two cases of fibroadenomas with infarction (rate $\sim 0.3 \%$ ). RESULTS: Two partially infarcted fibroadenomas were diagnosed on core biopsy and frozen section in an adolescent girl (13 years old) and in a young woman (25 years old), respectively. No preceding fine-needle aspiration biopsy was performed in these cases, nor were the patients pregnant or lactating at the time of the diagnosis. CONCLUSION: Spontaneous infarction within fibroadenoma is a rare phenomenon in younger patients. The presence of necrosis on core biopsy or frozen section should be cautiously interpreted and is not a sign of malignancy.

Smajlović D, Salihović D, Ibrahimagić OC, Sinanović $\mathrm{O}$. Characteristics of stroke in young adults in Tuzla Canton, Bosnia and Herzegovina. Coll Antropol. 2013 Jun;37(2):515-9.

University of Tuzla, Tuzla University Clinical Centre, Medical Faculty, Department of Neurology, Tuzla, Bosnia and Herzegovina.

The aim of the study was to analyze stroke in young adults in Tuzla Canton, Bosnia and Herzegovina. From January 2001 to December 2005, 3864 patients with first-ever stroke were admitted at the Department of Neurology Tuzla. A retrospective analysis of risk factors, stroke types, severity and one month outcome in all young adults (18-45 years of age) with first-ever stroke was carried out. Out of total, there were 154 (4\%) young adults with stroke. Mean age was $38.8+/-5.7$ years and $47 \%$ were women. The leading risk factors were smoking (56\%) and hypertension (45\%). Subarachnoid hemorrhage (SAH) was more frequent in young adults compared with older patients ( $>45$ years of age) $(22 \%$ vs. $3.5 \%, \mathrm{p}<0.0001)$, intracerebral hemorrhage $(\mathrm{ICH})$ was similar in both groups ( $16.9 \%$ vs. $15.8 \%, \mathrm{p}=0.7$ ), but ischemic stroke (IS) was predominant stroke type in the older group (61\% vs. $74 \%, p=0.0004)$. Young adults had more frequent lacunar stroke (26.6\% vs. $16.1 \%, \mathrm{p}=0.01)$ and stroke due to other etiology $(8.5 \%$ vs. $1.8 \%, \mathrm{p}=0.0004)$ than stroke patients over 45 years of age. Stroke severity at admission was lower in young adults than in older patients ( $\mathrm{p}<0.0001)$, as well as mortality at one month $(11 \%$ vs. $30 \%$, p < 0.0001$)$. Favorable outcome (modified Rankin Scale $<$ or $=2$ ) had $71 \%$ of young adults compared with only $53 \%$ of patients in the older group $(\mathrm{p}=0.0003)$. Stroke in young adults in Tuzla Canton is rare. Risk factors profile, stroke types, severity and outcome at one month in young adults are different from those in older patients.

Subasi A. Classification of EMG signals using PSO optimized SVM for diagnosis of neuromuscular disorders. Comput Biol Med. 2013 Jun 1;43(5):57686. doi: 10.1016/j.compbiomed.2013.01.020. Epub 2013 Feb 27.

International Burch University, Faculty of Engineering and Information Technologies, Francuske Revolucije bb. Ilidza, Sarajevo, 71000, Bosnia and Herzegovina.

Support vector machine (SVM) is an extensively used machine learning method with many biomedical signal classification applications. In this study, a novel PSO-SVM model has been proposed that hybridized the particle swarm optimization (PSO) and SVM to improve the EMG signal classification accuracy. This optimization mechanism involves kernel parameter setting in the SVM training procedure, which significantly influences the classification accuracy. The experiments were conducted on the basis of EMG signal to classify into normal, neurogenic or myopathic. In the proposed method the EMG signals were decomposed into the frequency sub-bands using discrete wavelet transform (DWT) and a set of statistical features were extracted from these sub-bands to represent the distribution of wavelet coefficients. The obtained results obviously validate the superiority of the SVM method compared to conventional machine learning methods, and suggest that further significant enhancements in terms of classification accuracy can be achieved by the proposed PSO-SVM classification system. The PSO-SVM yielded an overall accuracy of 97.41\% on 1200 EMG signals selected from 27 subject records against $96.75 \%, 95.17 \%$ and $94.08 \%$ for the SVM, the k-NN and the RBF classifiers, respectively. PSO-SVM is developed as an efficient tool so that various SVMs can be used conveniently as the core of PSO-SVM for diagnosis of neuromuscular disorders.

Šerifović-Trbalić A, Demirović D, Cattin PC. Intensity-based hierarchical elastic registration using approximating splines. Int J Comput Assist Radiol Surg. 2013 Jun 23. [Epub ahead of print] 
Faculty of Electrical Engineering, University of Tuzla, Tuzla, Bosnia and Herzegovina.

PURPOSE: We introduce a new hierarchical approach for elastic medical image registration using approximating splines. In order to obtain the dense deformation field, we employ Gaussian elastic body splines (GEBS) that incorporate anisotropic landmark errors and rotation information. Since the GEBS approach is based on a physical model in form of analytical solutions of the Navier equation, it can very well cope with the local as well as global deformations present in the images by varying the standard deviation of the Gaussian forces. METHODS: The proposed GEBS approximating model is integrated into the elastic hierarchical image registration framework, which decomposes a nonrigid registration problem into numerous local rigid transformations. The approximating GEBS registration scheme incorporates anisotropic landmark errors as well as rotation information. The anisotropic landmark localization uncertainties can be estimated directly from the image data, and in this case, they represent the minimal stochastic localization error, i.e., the Cramér-Rao bound. The rotation information of each landmark obtained from the hierarchical procedure is transposed in an additional angular landmark, doubling the number of landmarks in the GEBS model. RESULTS: The modified hierarchical registration using the approximating GEBS model is applied to register 161 image pairs from a digital mammogram database. The obtained results are very encouraging, and the proposed approach significantly improved all registrations comparing the meansquare error in relation to approximating TPS with the rotation information. On artificially deformed breast images, the newly proposed method performed better than the state-of-the-art registration algorithm introduced by Rueckert et al. (IEEE Trans Med Imaging 18:712-721, 1999). The average error per breast tissue pixel was less than 2.23 pixels compared to 2.46 pixels for Rueckert's method. CONCLUSION: The proposed hierarchical elastic image registration approach incorporates the GEBS approximation scheme extended with anisotropic landmark localization uncertainties as well as rotation information. Our experimental results show that the proposed scheme improved the registration result significantly.

Štrbac B, Jokić VS. Evaluation of set-up errors in head and neck radiotherapy using electronic portal imaging. Phys Med. 2013 Jan 2. pii: S11201797(12)00208-6. doi: 10.1016/j.ejmp.2012.12.001. [Epub ahead of print]

International Medical Centres, Centre for Radiotherapy, Dvanaest beba bb, 78000 Banja Luka, Bosnia and Herzegovina.
INTRODUCTION: The aim of this study was to evaluate three-dimensional (3D) set-up errors and propose optimum margins for planning target volume (PTV) coverage in head and neck radiotherapy. METHODS: Thirty-five patients were included in the study. The total number of portal images studied was 632. Population systematic $(\Sigma)$ and random $(\sigma)$ errors for the patients with head and neck cancer were evaluated based on the portal images in the caudocranial longitudinal (CC) and left-right lateral (LR) direction measured in the anterior-posterior (AP) field, as well as from the images in the caudocranial longitudinal (CC) and dorsoventral lateral (DV) direction measured in the lateral (LAT) field. The values for the clinical-to-planning target volume (CTV-PTV) margins were calculated using ICRU Report 62 recommendations, along with Stroom's and van Herk's formulae. RESULTS: The standard deviations of systematic setup errors $(\Sigma)$ ranged from 1.51 to $1.93 \mathrm{~mm}$ while the standard deviations of random set-up $(\sigma)$ errors fell in between 1.77 and $1.86 \mathrm{~mm}$. The mean $3 \mathrm{D}$ vector length of displacement was $2.66 \mathrm{~mm}$. PTV margins calculated according to ICRU, Stroom's and van Herk's models were comprised between 1.95 and $6.16 \mathrm{~mm}$ in the three acquisition directions. DISCUSSION AND CONCLUSIONS: Based on our results we can conclude that a 6-mm extension of CTV to PTV margin, as the lower limit, is enough to ensure that $90 \%$ of the patients treated for head and neck cancer will receive a minimum cumulative CTV dose greater than or equal to $95 \%$ of the prescribed dose.

\section{Tomić V, Petrović O, Crnčević Orlić Ž, Mandić V. Gestational diabetes and pregnancy outcome - do we have right diagnostic criteria? J Matern Fetal Neonatal Med. 2013 Jun;26(9):854-9. doi: 10.3109/14767058.2013.776530. Epub 2013 Apr 12.}

Department of Gynecology and Obstetrics, Mostar Clinical Hospital, Kralja Tvrtka b.b., Mostar, Bosnia and Herzegovina.

OBJECTIVE: To determine thresholds of maternal glycemia at which specific adverse pregnancy outcomes occur in high-risk population. METHODS: A total of 1002 pregnant women with risk factors for gestational diabetes mellitus (GDM) underwent an originally modified glucose tolerance test (OGTT) with $75 \mathrm{~g}$ of glucose. Information on OGTT results and pregnancy outcomes were collected from database and medical records. RESULTS: Large for gestational age (LGA) newborn, infant's stay in the neonatal intensive care unit (NICU) $>24 \mathrm{~h}$, neonatal hyperbilirubinemia and cesarean section due to cephalopelvic disproportion were identified as specific GDM adverse outcomes. In the study group of participants with one or more specific GDM adverse outcomes, mean glycemic values 
during the modified OGTT $(4.2 \pm 1.0 \mathrm{mmol} / \mathrm{L}$ at $0 \mathrm{~min}$, $6.8 \pm 1.7 \mathrm{mmol} / \mathrm{L}$ at $30 \mathrm{~min}, 7.9 \pm 2.1 \mathrm{mmol} / \mathrm{L}$ at $60 \mathrm{~min}$, $7.7 \pm 2.3 \mathrm{mmol} / \mathrm{L}$ at $90 \mathrm{~min}$ and $7.5 \pm 2.3 \mathrm{mmol} / \mathrm{L}$ at $120 \mathrm{~min}$ ) according to Student's t-test for independent samples were significantly higher than mean glycemic values in the control group of participants without specific adverse outcomes $(\mathrm{p}<0.001, \mathrm{p}=0.02, \mathrm{p}<0.001$, $\mathrm{p}<0.001, \mathrm{p}<0.001)$. CONCLUSION: This study provides additional data that support the acceptance of the newly recommended outcome-based GDM diagnostic criteria.

Vidic A, Ilić Z, Benedik L. Recent measurements of $234 \mathrm{U} / 238 \mathrm{U}$ isotope ratio in spring waters from the Hadzici area. J Environ Radioact. 2013 Jun;120:613. doi: 10.1016/j.jenvrad.2013.01.005. Epub 2013 Feb 11.

Institute for Public Health FBIH, M. Tita 9, 71000 Sarajevo, Bosnia and Herzegovina.

The Hadzici area has become interesting for investigation since depleted uranium ammunition had been employed in 1995 during the NATO air strike campaign in Bosnia and Herzegovina. The purpose of this study is to determine uranium concentration and (234) $\mathrm{U} /(238) \mathrm{U}$ activity ratio in the spring waters of this area and to investigate their relationship, as well as spatial variations. The spring water samples were taken at 18 sites in total. For the determination of uranium radioisotopes, radiochemical separation procedure followed by alpha-particle spectrometry was applied. Uranium concentration in analyzed waters range from 0.15 to $1.12 \mu \mathrm{g} / \mathrm{L}$. Spring waters from carbonate based sediments have a lower uranium concentration of between 0.15 and $0.43 \mu \mathrm{g} / \mathrm{L}$, in comparison to waters sampled within sandstone-based sediments ranging from 0.53 to $1.12 \mu \mathrm{g} / \mathrm{L}$. Dissolved uranium shows significant spatial variability and correlation with bedrock type confirmed by Principal Component Analysis and Hierarchical Cluster Analysis. The majority of the analyzed waters have a (234) $\mathrm{U} /(238) \mathrm{U}$ activity ratio ranging from 1.02 to 1.90 , of which half of the results range between 1.02 and 1.16. No apparent depleted uranium (DU) contamination was observed, as (234) $\mathrm{U} /(238) \mathrm{U}$ activity ratio is dependent on geochemical conditions in the environment. Even though the tested spring waters demonstrate significant variability in uranium concentration, (234) $\mathrm{U} /(238) \mathrm{U}$ activity ratio and (234) $\mathrm{U}$ excess, waters with similar uranium isotopic signatures are observable within the region. The guidelines on the spatial redistribution of dissolved uranium (corresponding to (238) $\mathrm{U}$ mass concentration), along with (234) U/(238)U activity ratios were provided by the Inverse Distance Weighting (IDW) method. Waters having similar isotopic signature have been delineated.

\section{Vranić S, Hes O, Grossmann P, Gatalica Z. Low frequency of HIF- $1 \alpha$ overexpression in germ cell tumors of the testis. Appl Immunohistochem Mol Morphol. 2013 Mar;21(2):165-9. doi: 10.1097/ PAI.0b013e31825e00b7.}

Department of Pathology, Clinical Center of the University of Sarajevo, Sarajevo, Bosnia and Herzegovina.

Cellular hypoxia is a hallmark of cancer. Hypoxiainducible factor-1 $\alpha$ (HIF-1 $\alpha$ ) and von Hippel-Lindau protein (pVHL) are the key mediators of cellular response to hypoxia. Little is known about their role in germ cell tumors of the testis. We therefore examined their status in a cohort of germ cell tumors of the testis. Thirty-six primary germ cell tumors of the testis (11 seminomas, 24 mixed germ cell tumors, and 1 case of pure intratubular germ cell neoplasia) were included in the study. HIF- $1 \alpha$ and pVHL expression were studied using immunohistochemical (IHC) methods in the tumor and adjacent benign tissue. Selected cases with a low pVHL expression were further tested for genetic alterations using polymerase chain reaction. HIF-1 $\alpha$ protein expression was not detectable in adjacent atrophic seminiferous tubules. In contrast, HIF-1a was expressed in one third of the malignancies, but in a low percentage of cells (mean, $3 \%$; range, $0 \%$ to $20 \%$ ). No difference in HIF-1a expression was observed between seminomas and nonseminomas $(\mathrm{P}=0.71)$. pVHL was expressed in atrophic tubular epithelium and in the Leydig cells, whereas a substantial loss of pVHL expression was observed in germ cell tumors regardless of the histologic type (mean, $45.6 \%$; range, $0 \%$ to $100 \%$ ). No genetic alterations of the VHL gene were observed in the cases with low pVHL expression. No significant correlation between HIF- $1 \alpha$ and pVHL expression was observed $(\mathrm{P}=0.16)$. Germ cell tumors of the testis, regardless of the histologic type, are characterized by consistently low HIF-1a protein overexpression and a partial loss of pVHL without underlying VHL gene alterations. Further studies are necessary to clarify the functional importance of such alterations in testicular germ cell tumors.

Vranić S, Schmitt F, Sapino A, Costa JL, Reddy S, Castro M, Gatalica Z. Apocrine carcinoma of the breast: A comprehensive review. Histol Histopathol. 2013 Jun 17. [Epub ahead of print]

Department of Pathology, Clinical Center of the University of Sarajevo, Sarajevo, Bosnia and Herzegovina; and Department of Medical Sciences, University of Turin, Turin, Italy.

Apocrine carcinoma of the breast is a rare, special type of breast carcinoma showing distinct morpho- 
logic, immunohistochemical and molecular genetic features. Apocrine epithelium has a characteristic steroid receptor profile that is estrogen receptor and progesterone receptor negative and androgen receptor positive. This combination of morphologic and immunohistochemical characteristics is essential for the proper recognition of the apocrine carcinomas. Strictly defined, apocrine carcinomas express either Her-2/ neu or EGFR, which along with androgen receptor positivity make patients with the apocrine carcinoma eligible for targeted therapies.

Zerem E, Omerović S. Comments on the article about the treatment of infected pancreatic necrosis. Surg Endosc. 2013 Jun 19. [Epub ahead of print]
Department of Gastroenterology, University Clinical Center Tuzla, Trnovac bb, 75000, Tuzla, Bosnia and Herzegovina.

No abstract available.

Zerem E, Omerović S, Imširović B. Is surgical cholecystectomy better than percutaneous in treatment of acute cholecystitis in patients unfit for surgery? J Gastrointest Surg. 2013 Aug;17(8):1542-3. doi: 10.1007/s11605-013-2205-6. Epub 2013 Apr 20.

Department of Gastroenterology, University Clinical Center Tuzla, Tuzla, Bosnia and Herzegovina.

No abstract available. 